\title{
Gender and Political Conservatism as Predictors of Blaming Asian Victims of Hate Crimes in the U.S. during the COVID-19 Pandemic
}

\author{
Niwako Yamawaki, Jane Green, Alice Nuo-Yi Wang, Samuel Eli Castillo, Yuki Nohagi \\ Department of Psychology, Brigham Young University, Provo, Utah, USA \\ Email: niwako_yamawaki@byu.edu
}

How to cite this paper: Yamawaki, N., Green, J., Wang, A. N.-Y., Castillo, S. E., \& Nohagi, Y. (2021). Gender and Political Conservatism as Predictors of Blaming Asian Victims of Hate Crimes in the U.S. during the COVID-19 Pandemic. Psychology, 12, 1184-1197.

https://doi.org/10.4236/psych.2021.128073

Received: July 1, 2021

Accepted: August 1, 2021

Published: August 4, 2021

Copyright $\odot 2021$ by author(s) and Scientific Research Publishing Inc. This work is licensed under the Creative Commons Attribution International License (CC BY 4.0).

http://creativecommons.org/licenses/by/4.0/

(c) (i) Open Access

\begin{abstract}
The purpose of this study was to investigate the potential impact of U.S. government official's comments regarding the source of COVID-19 on individuals' perceptions and tendencies to blame Asian victims of hate crimes in the U.S. Moreover, we examined how political conservatism and beliefs about the origin and spreading of COVID-19 impact participants' victim blaming toward Asian victims of hate crimes. Participants ( $N=100 ; 46$ women, 54 men) were recruited via Amazon's Mechanical Turk (MTurk). Participants were randomly assigned to read one of the two scenarios that either discussed COVID-19 with no direct inferences of blame toward the origin of COVID-19 or with directly placed blame on the origin of COVID-19. There were no significant main effects of the scenario or participants' gender on blaming the victim. However, we found that men who were presented COVID-19 origin information were more likely to blame Asian victims compared to men who were not given origin information. Moreover, political conservatism was a significant predictor of blaming Asian victims of hate crimes. Possible explanations for the results and future research directions were discussed.
\end{abstract}

\section{Keywords}

Anti-Asian Hate Crimes, Victim Blaming, Political Conservatism, Government Official, COVID-19

\section{Introduction}

Acquiring its name from the crown-resembling spikes on its outer layer, coronavirus is a respiratory disease attributed to severe acute respiratory syndrome 
coronavirus 2 (SARS-CoV-2; Shereen et al., 2020). The outbreak of coronavirus, also referred to as COVID-19, has led to millions of cases and deaths worldwide (World Health Organization [WHO], 2021). Nearing the end of 2019, researchers in China discovered multiple cases of pneumonia with no known origin. It was suspected that a fish market in Wuhan, China, was the original source of these pneumonia cases. However, further investigation exposed the viral nature of the infection and ruled out the fish market as a sole source (Guo et al., 2020; Shereen et al., 2020). This virus was named the coronavirus by Chinese researchers and later labeled as COVID-19 by the International Committee on Taxonomy of Viruses (Shereen et al., 2020). Within the first month, a total of 9,720 cases and 213 deaths were confirmed in China. By the end of the second month, at least 53 countries in every continent, excluding Antarctica, had confirmed cases of COVID-19, and the highest rates of infection were found in China, South Korea, Iran, and Italy (WHO, 2020a; WHO, 2020b). In an effort to slow down the spread of COVID-19 and encourage countries to proceed with containment procedures, WHO officially classified the outbreak of COVID-19 as a pandemic in March of 2020 (WHO, 2020c).

After an increase in cases, there were also economic struggles and disruptions. China's economy was affected negatively, and this pattern was spreading worldwide (McKibbin \& Fernando, 2021). In addition to economic concerns, COVID-19 began to have an impact on mental health, and this included inflated levels of suicidal ideation and substance abuse (Czeisler et al., 2020; Khan et al., 2020). Following the patterns of the SARS and MERS outbreaks, COVID-19 caused increases of anxiety and fear in individuals (Usher et al., 2020). Increased fear and anxiety, alongside changes in the environment, led to blame, closed-mindedness, and acts of discrimination (Usher et al., 2020). Within China, citizens of Wuhan were the main targets of blame for the spread of the virus. Furthermore, the Chinese population in general became the targets of blame at an international level (Usher et al., 2020).

The U.S. experienced its first positive case of COVID-19 in January of 2020, and within two months, the number of cases grew to over 235,000. By early April of 2020, cases had spread to every state within the U.S., and the death count exceeded 5000 (Omer et al., 2020). As seen in other countries, the rapid spread of cases led to increased levels of anxiety and fear (Usher et al., 2020). In the U.S., government officials were responsible for taking that fear and encouraging the narrative of blaming toward China, demanding reparations, and leading toward more Anti-Chinese attitudes (Alshahrani, 2021). A disunited political climate combined with the tension against China made the COVID-19 pandemic an opportune time for government officials to accrue public favor and use the blame against China for their own political gain (Mian \& Khan, 2020). Political leaders even began to refer to the virus as the "Chinese-virus," and this resulted in more blame (Barreneche, 2020). Due to the heavy influence of mainstream media, many individuals in the U.S. began to view China as the main source of the outbreak, held China accountable for many of the negative consequences of 
the pandemic, and began to ostracize and otherize Asians (Barreneche, 2020; Gover et al., 2020). Alshahrani (2021) found that across eight major media platforms in the U.S., $76 \%$ of the articles shared regarding COVID-19 viewed China negatively.

The striking prevalence of Anti-Chinese prejudice led to more Asians being targets of discrimination, and this brought the level of Anti-Asian hate crimes in the U.S. to the highest it had been in over a decade (Gover et al., 2020). Stop AAPI Hate, an advocacy platform for Asian Americans and Pacific Islanders, received notice of over 2800 cases of Anti-Asian hate crimes in 2020 (Cabral, 2021). In the same year, the number of Anti-Asian hate crimes had increased by approximately $150 \%$ (Yam, 2021). Examples of crimes included the following: the beating and death of an 84-year-old Thai immigrant living in San Francisco, California, who was attacked during a morning walk; the stabbing of two Asian women at a bus stop in San Francisco, whose attacker walked away freely; the assault with a hammer of an Asian American woman living in New York City, whose assailant was angry she refused to take off her mask; and the murder of eight people in Atlanta, Georgia, when a shooter went on a rampage to various Asian spas (Cabral, 2021).

From the severity of the pandemic itself to the rapidly increased number of hate crimes that Asians experienced as a result, it was crucial to investigate reasons hate crimes against Asian suddenly increased, and how today's highly politicized perceptions of the origin of COVID-19 would impact on the attitudes individuals have toward Asians. Furthermore, it was indispensable to explore some demographic and psychological correlates of negative attitudes toward Asians. As such, the study results may be helpful to develop promising and effective interventions for ameliorating hate crimes against Asians. Therefore, the purpose of the present study was to examine peoples' perceptions toward Asian victims of COVID-19-related hate crimes. Specifically, we focused on 1) the relationship between politically biased information and victim blaming, 2) the effect of political conservatism and victim blaming, and 3) if the belief that China is responsible for the pandemic predicts the strength of victim blaming. This topic was warranted due to the vast increase of Asian-related hate crimes beginning after the increase of positive COVID-19 cases.

When faced with disease threats, it is common for the individuals negatively affected to place blame on and discriminate against the racial group that is thought to have caused the outbreak (Li \& Nicholson, 2021). During the SARS epidemic in 2003, Asian Americans in the New York Chinatown were stigmatized and faced losses to their restaurant businesses despite having no known SARS cases in the area (Eichelberger, 2007). Asian Americans during the COVID-19 pandemic have faced more severe harassment. In fact, the responses to the pandemic are hardly only about the infectious disease themselves but also a reflection of political conflict and control. Within the U.S., xenophobic news headlines that called the coronavirus the "Wuhan virus" have aggravated fear and misconceptions of the etiology of the virus and further promoted discrimi- 
nation toward minorities who were affected by the pandemic to a greater extent with which to begin (Centers for Disease Control and Prevention, 2020; Leach, 2020). Furthermore, naming a virus based on the location that it was first found makes conversations about the pandemic politically charged.

Victim blaming in the present study refers to the behavior of attributing responsibility of a COVID-19-related hate crime solely on the victim because of the public's racialization of COVID-19. As noted by Mason (2015), racial discrimination increases by associating a disease with a specific geographic location of where it originated and by believing that a specific race residing at that location is more prone to this disease. Throughout the COVID-19 pandemic, many individuals have blamed Asian victims of hate crimes instead of providing support to these victims. This is due to the possible belief that since the virus is currently known to have originated from China, Asians are more vulnerable to catching COVID-19. People with this belief would be likely to attribute the causes and consequences of COVID-19 to Asians (e.g., "the culprits" of spreading the virus to others in the U.S. population). Such beliefs were found in a recent study to have significant workplace consequences in which COVID-19-related blaming was associated with a lower tendency to select Asian employees and an increased level of social distancing with Asians in the work-place (Gardner et al., 2021). This blaming perspective supports the belief that Asians deserve to be treated negatively. Therefore, we hypothesized that participants who received politically biased information that hold Chinese individuals responsible for the COVID-19 pandemic would blame the Asian victims of hate crimes more than the participants who received unbiased, accurate information regarding the COVID-19 pandemic.

People with a more conservative political view, compared to people with a more liberal view, tend to focus more on the responsibilities of individuals regardless of the positive or negative nature of the situation, and this leads to individual blame as opposed to system blame when situations arise (Brown \& Johnson, 1999; Mancini \& Pickett, 2017). Political conservatism has been associated with victim blaming toward rape victims, welfare clients, and theft victims, and the investigation of political conservatism and blaming Asian victims of hate crimes is warranted (Gravelin et al., 2019; Lambert \& Raichle, 2000; Mancini \& Pickett, 2017; Williams, 1984). Right-wing authoritarianism (RWA) refers to one's attitude toward following traditional conservative values, dogmatism, and submitting to and being supportive of authority (Altemeyer, 1988; Manson, 2020; Nicol \& France, 2018). Previous researchers have concluded that RWA is positively related to prejudice. Specifically, people who have strong RWA attitudes are more likely to form a prejudice toward minorities, outgroups, and people with less conservative attitudes (Sibley \& Duckitt, 2008).

Previous researchers who conducted studies involving victim blaming have also included RWA as an important predictor along with measures that predict one's obedience to authority (Niemi \& Young, 2016). In the context of COVID-19, Prichard and Christman (2020) found that authoritarianism was 
associated with a less overall concern of the effects of the pandemic and a reduced tendency to engage in preventative measures such as wearing a mask. In addition, participants who had a more authoritarian attitude were also more likely to blame China for the COVID-19 pandemic (Prichard \& Christman, 2020). As such, we hypothesized that participants who had more conservative political beliefs would blame Asian victims of hate crimes more than participants who had more liberal political beliefs. Two exploratory variables that we examined were how individuals' perceptions and tendencies to blame the victim changed based on their belief of the origin and the cause of COVID-19. The belief that Chinese caused the pandemic implies that China is responsible for starting the COVID-19 pandemic, and this belief focuses on the origin of COVID-19. The belief that Chinese spread COVID-19, however, implies that China is responsible for amplifying the effects of COVID-19 to the U.S., and this focuses on the damages of COVID-19. Making such distinctions helps us gain a better understanding of the logic behind victim blaming during the COVID-19 pandemic and makes the findings more precise. As such, exploratory analyses were examined using these two potential predictors alongside victim blaming. Moreover, we also examined participants' demographics characteristics as potential predictors of blaming Asian victims of hate crimes.

\section{Method}

\section{Participants}

One-hundred participants (46 women, 54 men) were recruited from Amazon's Mechanical Turk (MTurk) for the present study. There were 50 participants (25 women, 25 men) in the control group and 50 participants ( 21 women, 29 men) in the experimental group. All participants were required to 1) be at least 18 years old, 2) be residents of the United States, 3) have an MTurk account, and 4) have a previous approval rating of greater than $95 \%$. Due to the items and responses of the dependent variable centering around hate crimes directed toward Asian individuals, individuals of Asian descent were excluded from this study for the ethical protection of participants and to ensure that responses were not biased. One participant entered their year of birth instead of their age in years. As such, based on the year of data collection, an age was approximated for this participant. Therefore, the age range of participants was $21-69(M=37.57, S D$ = 11.26), and participants selected their race/ethnicity as White/Caucasian $(N=$ $82 ; 82 \%)$, Black/African-American $(N=12 ; 12 \%)$, Hispanic/Latinx $(N=3 ; 3 \%)$, and more than one race $(N=3 ; 3 \%)$. All participants were compensated with $\$ 1.75$ toward their MTurk account.

\section{Materials}

\section{Scenarios}

Participants received one of two different scenarios (i.e., control group scenario, experimental group scenario) that consisted of the manipulation. Within the 
control group scenario, COVID-19 was discussed with no indirect inferences of blame toward the origin of the virus. Within the experimental group scenario, however, COVID-19 was discussed using language that indirectly placed blame on the origin of the virus. The following is the control group scenario with the experimental group scenario in brackets:

\section{The following paragraphs contain information about the COVID-19 pandemic:}

Currently, 4.8 million Americans are infected and 158,000 of them have died from the coronavirus [Chinese-born virus that first broke out in $\mathrm{Wu}$ han, China]. Unlike the regular flu, COVID-19 [-called the Wuhan virus-] could be airborne, meaning that tiny droplets remaining in the air could infect others even after the ill person is no longer near. The coronavirus [Wuhan virus] situation is changing rapidly. Since this disease is caused by a new virus, people do not have immunity to it, and a vaccine may be many months away. Doctors and scientists are working to estimate the mortality rate of COVID-19 [the Chinese-born virus], but at present, it is thought to be substantially higher than that of most strains of the flu. On Sunday, August 2 nd, a government official predicted that the death toll from the coronavirus pandemic ravaging the country might reach as high as 350,000 in the United States, far higher than the estimates made in July, even as he pressed states to begin reopening the shattered economy.

\section{The Blame Attribution Scale}

The Blame Attribution Scale was created for the purpose of the current study. This measure was utilized to examine how much participants blamed (i.e., victim blaming) the Asian individual in each of the ten, real-world situations they read in which Asian individuals were attacked because of COVID-19. All situations were adapted from news reports. Examples included:

A Chinese man is walking down the street around a popular shopping area. A man comes up to him and begins verbally assaulting him. He says to him, "I don't want your Coronavirus in my country" and then punches him.

An Asian woman and her friend walk into an elevator on their way home from watching a special screening. Four white men enter the elevator and one man asks if they have the coronavirus.

After reading the situations, participants then responded to the items of the Blame Attribution Scale. There was a total of 10 items, and one item was reverse scored. Example items included "The Chinese man is somehow responsible for this incident." and "This woman and her friend are responsible for creating this situation." Participants responded on a Likert scale from 1 "Strongly disagree" to 7 "Strongly agree." Higher scores were indicative of higher levels of blame toward Asian individuals. A principal component factor analysis was performed with a varimax rotation. The result of this analysis yielded a one-factor solution 
(based on eigenvalues $>1$ ), with $87 \%$ variance accounted for by this one factor. Cronbach's alpha for this measure was $\alpha=0.98$.

\subsection{The Right-Wing Authoritarianism Scale (RWA; Altemeyer, 2006)}

A revised version of the RWA Scale was utilized to examine participants' political conservatism. There was a total of 22 items, and 10 items were reverse scored. Two of the 22 items were not used in the final analyses as indicated by Altemeyer (2006). Example items included "Our country needs free thinkers who have the courage to defy traditional ways, even if this upsets many people." and "What our country really needs is a strong, determined leader who will crush evil, and take us back to our true path." Participants responded on a Likert scale from 1 "Strongly disagree" to 7 "Strongly agree." Higher scores were indicative of more political conservatism. Saunders and Ngo (2017) reported that this measure has a Cronbach's alpha of $\alpha=0.90$. Cronbach's alpha in this study was $\alpha=94$.

\subsection{Beliefs about Origin and Spreading of COVID-19}

For exploratory analyses, participants were asked two questions regarding their beliefs about COVID-19. To measure participants' beliefs about COVID-19 originating in China and being spread by Chinese individuals in the U.S., participants were asked 1) "Do you believe that the COVID-19 pandemic was caused by Chinese?" and 2) "Do you believe that Chinese spread the Coronavirus in the US?" Participants responded with either "Yes" or "No."

\section{Procedure}

All participants meeting the aforementioned inclusion criteria were eligible to participate in the current research study. They first saw this survey posted on MTurk. After clicking the Qualtrics.com link, participants were directed to the consent form. Next, they completed a demographics survey and then were randomized into either the control group or the experimental group. After reading the scenario, all participants then read 10 short, real-world examples of attacks toward Asian individuals related to COVID-19 that were taken from national newspaper websites. Participants then responded to the Blame Attribution Scale and the RWA Scale. Afterwards, participants received a debriefing form and their random ID. Participants inserted their random ID on MTurk to verify their completion of this study and to receive their compensation.

\section{Results}

\subsection{The Impact of Government Official's Comments on the Source of COVID-19}

To examine our main hypothesis of the impact of the government official's comments on the source of COVID-19, a 2 (scenario: control vs. experimental) 
$\times 2$ (participant gender) ANOVA was conducted on the Blame Attribution Scale. Contrary to our hypothesis, there were no significant main effects of the scenario or participants' gender on blaming the victim $(F[1,96]=0.61, p=n s ; F[1,96]$ $=0.02, p=n s$, respectively). The insignificant result of the scenario suggests that the government official's comments about the origin of COVID-19 did not impact respondents' attitudes toward Asian victims of violence. However, there was a significant scenario $\mathrm{x}$ participant gender interaction effect $(F[1,96]=2.76, p=$ 0.050). This interaction can be seen in Figure 1. Men in the experimental group showed a significant level of blame compared to men in the control group.

\subsection{The Predictive Roles of Political Conservatism and Beliefs about the Origin and Spreading of COVID-19}

To examine another objective of this study, simultaneous multiple regression analyses were conducted with political conservatism, one's beliefs that COVID-19 originated in China, and one's beliefs that Chinese individuals spread the COVID-19 in the U.S. as predictors of respondents' blame toward Asian victims of hate crimes. Since both beliefs were answered "Yes" or "No," we dummy coded these variables (yes $=1$, no $=0$ ) to conduct the analyses. The results revealed that political conservatism and one's beliefs about that the COVID-19 was spread by Chinese individuals in the U.S. were both significant $(\beta=0.28, p=$ 0.002 and $\beta=0.48, p<0.001$, respectively). That is, participants who endorsed a greater level of political conservatism and participants who believed that COVID-19 was spread by Chinese individuals in the U.S. tended to blame Asian victims more than participants who had lower levels of political conservatism and who did not believe that COVID-19 was spread by Chinese individuals. However, respondents' beliefs that COVID-19 originated in China was not a significant predictor of blaming $(\beta=0.05, p>0.05)$.

\section{Discussion}

The purpose of the current research study was to investigate how differences in

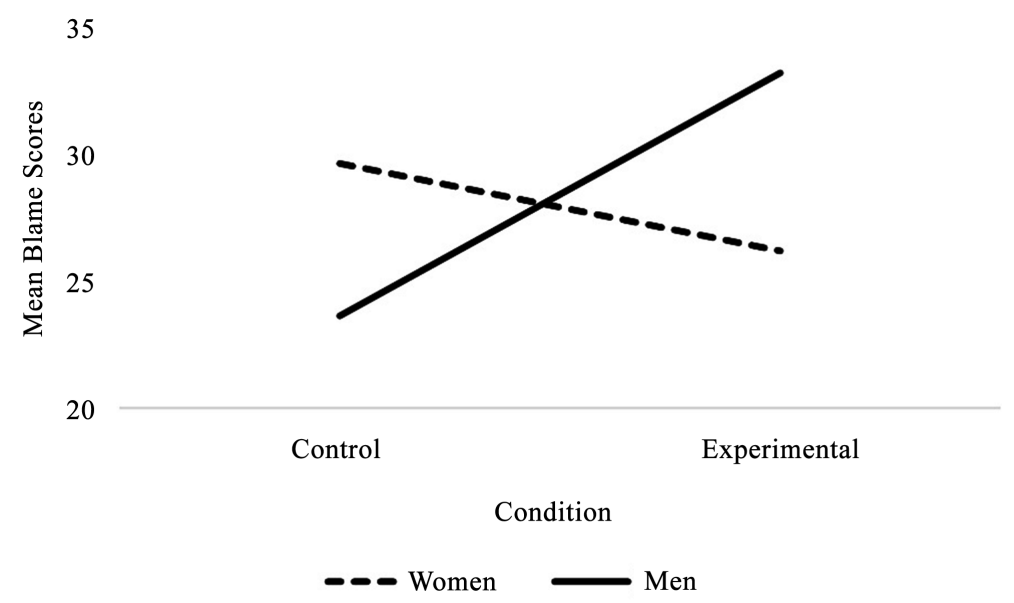

Figure 1. Interaction of gender and scenario condition. 
information would impact participants' perceptions of Asian hate crimes during the COVID-19 pandemic. We presented two conditions in which some participants received non-origin information about COVID-19 (i.e., control group) and other participants received origin information about COVID-19 (i.e., experimental group). Participants also received individual situations of violence that were depicted toward Asian victims of hate crimes, and we investigated how participants blamed these Asian victims. We hypothesized that participants exposed to the origin information about COVID-19 would be more likely to blame Asian victims of hate crimes compared to participants who received non-origin COVID-19 information. We further hypothesized that participants high in political conservatism would be more likely to blame Asian victims of hate crimes compared to participants low in political conservatism. Moreover, we ran exploratory analyses regarding beliefs about COVID-19 and demographics of participants related to blaming.

There was no main effect of the scenario in which participants were randomly assigned. As such, participants who received information about the origin of COVID-19 did not tend to blame Asian victims of hate crimes more than participants who did not receive information about the origin of COVID-19. One possible reason for this null, main effect could be because participants already had confirmed personal beliefs about COVID-19 (e.g., conspiracy theories; Enders et al., 2020). Therefore, this may have led information related to the origin of COVID-19 to have no impact on blaming tendencies. Moreover, participants may have generally been less reactive to the language used to describe COVID-19 (e.g., Wuhan virus) due to high exposure to the media (e.g., on the news, comments from government officials and staff).

There was also no main effect of gender (i.e., women, men). This result is contrary to previous researchers' findings regarding blame. In general, men, compared to women, tend to blame victims of various forms of violence (e.g., Grubb \& Turner, 2012; Pinciotti \& Orcutt, 2021). Furthermore, these findings are also contrary to gender differences found related to COVID-19 (Prichard \& Christman, 2020). One potential reason could be because the COVID-19 pandemic impacted everyone globally, and this occurred simultaneously. This is unlike other forms of violence (e.g., child abuse, intimate partner violence) that occur individually yet, which are still public health concerns. It is possible that there may be no main effect of gender differences regarding blaming due to the prevalence of COVID-19. Interestingly, however, there was a significant scenario and gender interaction. Men in the experimental group blamed Asian victims of hate crimes more than men in the control group. That is, men who were presented with COVID-19 origin information blamed Asian victims more than men who were not presented COVID-19 origin information. This may be due to men being more influenced by origin-related information compared to women. It may also be due to men being more influenced by power (e.g., legitimate power, such as a U.S. government official) than women. However, more research is needed to examine any possible gender differences in blaming related to COVID-19 and to 
examine further any potential main effects of gender.

As we hypothesized, we found that individuals higher in RWA (i.e., more politically conservative) blamed Asian victims more compared to individuals lower in RWA. This finding is regardless of scenario and participant gender. Furthermore, this finding is similar to previous researchers' findings that individuals high in RWA are more likely to blame victims (e.g., Canto et al., 2021; Spaccatini et al., 2019). Therefore, individuals who were more politically conservative were more likely to blame Asian victims compared to individuals who were less politically conservative. As such, it may be that individuals who are more politically conservative are more likely to blame victims during the COVID-19 pandemic compared to individuals who are more politically liberal. Future researchers should continue examining this variable as a predictor of blaming victims. It is recommended to educate individuals who hold greater political conservatism that blaming victims of hate crime has a detrimental impact on victims' psychological well-being.

We also examined participants' belief in the origin of COVID-19, and we found no effect of this belief on blaming Asian victims. A potential reason for this finding could be the acknowledgement of COVID-19 originating in China. Additionally, participants' belief of Chinese spreading COVID-19 to the U.S. was a significant predictor of blaming. As such, the more participants believed Chinese individuals spread COVID-19 to the U.S., the more they blamed Asian victims of hate crimes. Therefore, by acknowledging the origin of COVID-19-which was non-significant-and then acknowledging potential spreading-which was significant-may account for this significant finding. Individuals who are angry about the known origin may tend to believe that Chinese individuals spread the coronavirus to the U.S. due to the virus' origin.

We further explored participants' demographics. We found that younger individuals were more likely to blame the Asian victims compared to older individuals. This finding is contrary to previous findings related to age and blaming women victims of violence (e.g., Gracia \& Tomás, 2014). This finding may be explained by younger individuals potentially being more influenced by different forms of media (e.g., news outlets, online social platforms). Future researchers should examine age in relation to blaming Asian victims of hate crimes during this pandemic. Surprisingly, we found that participants who were more educated were more likely to blame Asian victims compared to participants with less educational obtainment. This finding is also contrary to findings related to educational obtainment and blaming women victims of violence (e.g., Gracia \& Tomás, 2014); however, this finding dovetails with recent findings of individuals with higher educational obtainment believing more in COVID-19 conspiracy theories (Stocia \& Umbreș, 2021). As such, it is possible that individuals with higher education may have more resources to which they can attribute blame compared to individuals with lower educational obtainment.

Participants were also asked the following question: "Have you been diag- 
nosed with COVID-19?" Participants who were diagnosed with COVID-19 ( $N=$ 15) blamed Asian victims more compared to the participants who had not been diagnosed with COVID-19 $(N=85)$. That is, participants who experienced a diagnosis, a possible variety of COVID-19 symptoms, and potential hospitalization were more likely to blame Asian victims compared to those without these experiences. Additional research is needed to examine the severity of COVID-19 symptoms and a prior diagnosis related to blame victimization of Asian victims.

\section{Implications}

This research study resulted in multiple implications. One implication is that this research study serves as a potential means to understand hate crimes toward Asians during the COVID-19 pandemic. Within the current research, we investigated potential predictors for the widespread blame directed toward Asians who have experienced hate crimes. A significant strength of this study is that we utilized news stories of real violent crimes toward Asians that were related to the COVID-19 pandemic. Moreover, this study was important in understanding individuals' perceptions of Asian hate crimes and how individuals' personal beliefs impact blame victimization. Indeed, personal beliefs (i.e., political conservatism, spreading of COVID-19) did predict higher levels of blaming Asian victims.

\section{Limitations}

One limitation of the current study is that our sample consisted predominantly of White, educated individuals. As such, this research study lacks diversity when discussing blaming a minority group (i.e., Asian victims of hate crimes in the U.S.). More diversity in future research studies should be obtained. Moreover, this study was conducted soon after COVID-19 cases exacerbated in the U.S. Much information regarding COVID-19 was unknown at this time (e.g., death rates, who is impacted most, direct symptoms of a positive diagnosis). As such, unknown variables (e.g., fear related to death rates) may have impacted the current study's results, and additional research is warranted since previously unknown, important information is now well-known.

\section{Future Directions}

Future researchers should obtain a larger sample size when examining how individuals blame Asian victims of hate crimes. A larger sample size would contribute to having higher power of detecting significant results. Moreover, researchers should also examine additional predictor variables, such as belief in a just world and social dominance orientation. These variables may contribute to reasons why individuals blame Asian victims of hate crimes. Moreover, researchers should also examine blaming tendencies in various populations, such as college students and religious individuals. There may be additional participants demographics that influence individuals' tendency to blame Asian victims during the COVID-19 pandemic. 


\section{Conflicts of Interest}

The authors declare no conflicts of interest regarding the publication of this paper.

\section{References}

Alshahrani, A. (2021). A Frame Analysis of the Language Used by Eight US Media to Describe the Role of China and Chinese in Spreading Covid-19 during Late January to Early June 2020. Journal of Language and Linguistic Studies, 17, 1129-1140. https://doi.org/10.17263/jlls.904136

Altemeyer, B. (1988). Enemies of Freedom: Understanding Right-Wing Authoritarianism. Jossey-Bass.

Altemeyer, B. (2006). The Authoritarians. https://theauthoritarians.org/

Barreneche, S. M. (2020). Somebody to Blame: On the Construction of the Other in the Context of the Covid-19 Outbreak. Society Register, 4, 19-32.

https://doi.org/10.14746/sr.2020.4.2.02

Brown, L. M., \& Johnson, S. D. (1999). Ethnic Consciousness and Its Relationship to Conservatism and Blame among African Americans. Journal of Applied Social Psychology, 29, 2465-2480. https://doi.org/10.1111/j.1559-1816.1999.tb00121.x

Cabral, S. (2021, May 21). Covid 'Hate Crimes' against Asian Americans on Rise. BBC News. https://www.bbc.com/news/world-us-canada-56218684

Canto, J. M., Martín, J. S., Perles, F., \& Vallejo, M. (2021). Persons Who Fear Freedom and Equality Are the Ones Who Most Blame Women Who Are Victims of Acquaintance Rape. Violence against Women, 27, 731-474.

https://doi.org/10.1177/1077801220909896

Centers for Disease Control and Prevention (2020, December 10). Increased Risk Factors for Exposure.

https://www.cdc.gov/coronavirus/2019-ncov/community/health-equity/racial-ethnic-di sparities/increased-risk-exposure.html

Czeisler, M. É., Lane, R. I., Petrosky, E., Wiley, J. F., Christensen, A., Njai, R., Weaver, M. D., Robbins, R., Facer-Childs, E. R., \& Barger, L. K. (2020). Mental Health, Substance Use, and Suicidal Ideation during the COVID-19 Pandemic-United States, June 24-30, 2020. Morbidity and Mortality Weekly Report, 69, 1049-1057.

https://doi.org/10.15585/mmwr.mm6932a1

Eichelberger, L. (2007). SARS and New York's Chinatown: The Politics of Risk and Blame during an Epidemic of Fear. Social Science \& Medicine, 65, 1284-1295.

https://doi.org/10.1016/j.socscimed.2007.04.022

Enders, A. M., Uscinski, J. E., Klofstad, C., \& Stoler, J. (2020). The Different Forms of COVID-19 Misinformation and Their Consequences. The Harvard Kennedy School (HKS) Misinformation Review, 1, 1-21.

https://nrs.harvard.edu/URN-3:HUL.INSTREPOS:37366466 https://doi.org/10.37016/mr-2020-48

Gardner, D. M., Briggs, C. Q., \& Ryan, A. M. (2021). It Is Your Fault: Workplace Consequences of Anti-Asian Stigma during COVID-19. Equality, Diversity and Inclusion: An International Journal. https://doi.org/10.1108/EDI-08-2020-0252

Gover, A. R., Harper, S. B., \& Langton, L. (2020). Anti-Asian Hate Crime during the COVID-19 Pandemic: Exploring the Reproduction of Inequality. American Journal of Criminal Justice, 45, 647-667. https://doi.org/10.1007/s12103-020-09545-1 
Gracia, E., \& Tomás, J. M. (2014). Correlates of Victim-Blaming Attitudes Regarding Partner Violence against Women among the Spanish General Population. Violence against Women, 20, 26-41. https://doi.org/10.1177/1077801213520577

Gravelin, C. R., Biernat, M., \& Bucher, C. E. (2019). Blaming the Victim of Acquaintance Rape: Individual, Situational, and Sociocultural Factors. Frontiers in Psychology, 9, Article ID: 2422. https://doi.org/10.3389/fpsyg.2018.02422

Grubb, A., \& Turner, E. (2012). Attribution of Blame in Rape Cases: A Review of the Impact of Rape Myth Acceptance, Gender Role Conformity and Substance Use Victim Blaming. Aggression and Violent Behavior, 17, 443-452.

https://doi.org/10.1016/j.avb.2012.06.002

Guo, Y., Cao, Q., Hong, Z., Tan, Y., Chen, S., Jin, H., Tan, K., Wang, D., \& Yan, Y. (2020). The Origin, Transmission and Clinical Therapies on Coronavirus Disease 2019 (COVID-19) Outbreak-An Update on the Status. Military Medical Research, 7, Article No. 11. https://doi.org/10.1186/s40779-020-00240-0

Khan, S., Siddique, R., Li, H., Ali, A., Shereen, M. A., Bashir, N., \& Xue, M. (2020). Impact of Coronavirus Outbreak on Psychological Health. Journal of Global Health, 10, Article ID: 010331. https://doi.org/10.7189/jogh.10.010331

Lambert, A. J., \& Raichle, K. (2000). The Role of Political Ideology in Mediating Judgments of Blame in Rape Victims and Their Assailants: A Test of the Just World, Personal Responsibility, and Legitimization Hypotheses. Personality and Social Psychology Bulletin, 26, 853-863. https://doi.org/10.1177/0146167200269010

Leach, M. (2020, March 6). Echoes of Ebola: Social and Political Warnings for the COVID-19 Response in African Settings. Somatosphere.

http://somatosphere.net/forumpost/echoes-of-ebola/

Li, Y., \& Nicholson, H. L. Jr. (2021). When "Model Minorities" Become "Yellow Peril"-Othering and the Racialization of Asian Americans in the COVID-19 Pandemic. Sociology Compass, 15, Article ID: e12849. https://doi.org/10.1111/soc4.12849

Mancini, C., \& Pickett, J. T. (2017). Reaping What They Sow? Victim-Offender Overlap Perceptions and Victim Blaming Attitudes. Victims \& Offenders, 12, 434-466. https://doi.org/10.1080/15564886.2015.1093051

Manson, J. H. (2020). Right-Wing Authoritarianism, Left-Wing Authoritarianism, and Pandemic-Mitigation Authoritarianism. Personality and Individual Differences, 167, Article ID: 110251. https://doi.org/10.1016/j.paid.2020.110251

Mason, K. A. (2015). H1N1 Is Not a Chinese Virus: The Racialization of People and Viruses in Post-SARS China. Studies in Comparative International Development, 50, 500-518. https://doi.org/10.1007/s12116-015-9198-y

McKibbin, W. J., \& Fernando, R. (2021). The Global Macroeconomic Impacts of COVID-19: Seven scenarios. Asian Economic Papers, 20, 1-30. https://doi.org/10.1162/asep a 00796

Mian, A., \& Khan, S. (2020). Coronavirus: The Spread of Misinformation. BMC Medicine, 18, Article No. 89. https://doi.org/10.1186/s12916-020-01556-3

Nicol, A. A. M., \& France, K. (2018). Mindfulness: Relations with Prejudice, Social Dominance Orientation, and Right-Wing Authoritarianism. Mindfulness, 9, 1916-1930. https://doi.org/10.1007/s12671-018-0938-8

Niemi, L., \& Young, L. (2016). When and Why We See Victims as Responsible: The Impact of Ideology on Attitudes toward Victims. Personality and Social Psychology Bulletin, 42, 1227-1242. https://doi.org/10.1177/0146167216653933

Omer, S. B., Malani, P., \& Del Rio, C. (2020). The COVID-19 Pandemic in the US: A 
Clinical Update. JAMA, 323, 1767-1768. https://doi.org/10.1001/jama.2020.5788

Pinciotti, C. M., \& Orcutt, H. K. (2021). Understanding Gender Differences in Rape Victim Blaming: The Power of Social Influence and Just World Beliefs. Journal of Interpersonal Violence, 36, 255-275. https://doi.org/10.1177/0886260517725736

Prichard, E. C., \& Christman, S. D. (2020). Authoritarianism, Conspiracy Beliefs, Gender and COVID-19: Links between Individual Differences and Concern about COVID-19, Mask Wearing Behaviors, and the Tendency to Blame China for the Virus. Frontiers in Psychology, 11, 1-7. https://doi.org/10.3389/fpsyg.2020.597671

Saunders, B. A., \& Ngo, J. (2017). The Right-Wing Authoritarianism Scale. In V. Zeigler-Hill, \& T. K. Shackelford (Eds.), Encyclopedia of Personality and Individual Differences (pp. 71-76). Springer International Publishing. https://doi.org/10.1007/978-3-319-28099-8 1262-1

Shereen, M. A., Khan, S., Kazmi, A., Bashir, N., \& Siddique, R. (2020). COVID-19 Infection: Origin, Transmission, and Characteristics of Human Coronaviruses. Journal of Advanced Research, 24, 91-98. https://doi.org/10.1016/j.jare.2020.03.005

Sibley, C. G., \& Duckitt, J. (2008). Personality and Prejudice: A Meta-Analysis and Theoretical Review. Personality and Social Psychology Review, 12, 248-279.

https://doi.org/10.1177/1088868308319226

Spaccatini, F., Pacilli, M. G., Giovannelli, I., Roccato, M., \& Penone, G. (2019). Sexualized Victims of Stranger Harassment and Victim Blaming: The Moderating Role of Right-Wing Authoritarianism. Sexuality \& Culture: An Interdisciplinary Quarterly, 23, 811-825. https://doi.org/10.1007/s12119-019-09592-9

Stocia, C. A., \& Umbreș, R. (2021). Suspicious Minds in Terms of Crisis: Determinants of Romanians' Beliefs in COVID-19 Conspiracy Theories. European Societies, 23, S246-S261. https://doi.org/10.1080/14616696.2020.1823450

Usher, K., Durkin, J., \& Bhullar, N. (2020). The COVID-19 Pandemic and Mental Health Impacts. International Journal of Mental Health Nursing, 29, 315-318. https://doi.org/10.1111/inm.12726

Williams, S. (1984). Left-Right Ideological Differences in Blaming Victims. Political Psychology, 5, 573-581. https://doi.org/10.2307/3791228

World Health Organization (2020a, January 31). Novel Coronavirus (2019-nCoV) Situation Report-11.

https://www.who.int/docs/default-source/coronaviruse/situation-reports/20200131-sitr ep-11-ncov.pdf?sfvrsn=de7c0f7 4

World Health Organization (2020b, February 29). Novel Coronavirus (2019-nCo V) Situation Report-40.

https://www.who.int/docs/default-source/coronaviruse/situation-reports/20200229-sitr ep-40-covid-19.pdf?sfvrsn=849d0665 2

World Health Organization (2020c, March 12). WHO Announces COVID-19 Outbreak a Pandemic.

http://www.euro.who.int/en/health-topics/health-emergencies/coronavirus-covid-19/n ews/news/2020/3/who-announces-covid-19-outbreak-a-pandemic

World Health Organization (2021, May 16). COVID-19 Weekly Epidemiological Update. https://www.who.int/emergencies/diseases/novel-coronavirus-2019/situation-reports

Yam, K. (2021, March 9). Anti-Asian Hate Crimes Increased by Nearly 150\% in 2020, mostly In N.Y. and L.A., New Report Says. NBC News.

https://www.nbcnews.com/news/asian-america/anti-asian-hate-crimes-increased-nearl y-150-2020-mostly-n-n1260264 